\title{
Erratum to: Spatial variability in DMSP-lyase activity along an Atlantic meridional transect
}

\author{
Thomas G. Bell • Gill Malin • Young-Nam Kim • \\ Michael Steinke
}

Received: 8 April 2010/ Accepted: 14 April 2010/Published online: 13 May 2010

(C) Springer Basel AG 2010

\section{Erratum to: Aquat Sci 69 (2007) 320-329 DOI 10.1007/s00027-007-0894-1}

It has come to our attention that there was a consistent error in the calculation of the DMSP-lyase activity (DLA) values presented in Bell et al. (2007). We present the corrected values to enable accurate comparison with past and future studies. The relative patterns discussed in Bell et al. (2007) and the conclusions drawn are broadly unaffected. Figures 1, 2, 3, 4 (below) use the recalculated data and replace the plots shown in Bell et al. (2007). We also present the recalculated DLA data in a corrected version of Table 1 from Bell et al. (2007), which still demonstrates the same trends when comparing pre-dawn and late-morning CTD casts.

When considering the recalculated DLA data, two points should be noted. Firstly, the potential turnover times calculated in Bell et al. (2007) are incorrect. The corrected values are in closer agreement with the $5 \mathrm{~min}$ average turnover time presented in Harada et al. (2004), with

The online version of the original article can be found under doi:10.1007/s00027-007-0894-1.

T. G. Bell $(\bowtie) \cdot$ G. Malin

Laboratory for Global Marine and Atmospheric Chemistry

(LGMAC), School of Environmental Sciences,

University of East Anglia, Norwich, Norfolk NR4 7TJ, UK

e-mail: Thomas.Bell@uea.ac.uk

\section{Y.-N. Kim}

National Oceanography Centre, European Way,

Southampton SO14 3ZH, UK

\section{Steinke}

Department of Biological Sciences, University of Essex, Wivenhoe Park, Colchester, Essex CO4 3SQ, UK recalculated potential DMSPp turnover times for our entire study ranging from $0.02 \mathrm{~min}$ (approx. $1 \mathrm{~s}$ ) to $35 \mathrm{~min}$. The recalculated average turnover times for sections I/III and II/ IV are 3.8 and $5.7 \mathrm{~min}$, respectively. Recalculating the turnover times using total DMSP generates average values of $7.0 \mathrm{~min}$ for sections I/III and $11.1 \mathrm{~min}$ for sections II/IV.

Secondly, whilst the ${ }^{14} \mathrm{C}$-derived phytoplankton carbon fixation and recalculated DLA:TChl $a$ ratio data (Fig. 4) still demonstrate the same pattern as in Bell et al. (2007), the strength of correlation between the two has reduced slightly (Spearman's $\rho$ changes from -0.57 to -0.50 ), although this is still a significant result $(p<0.05, n=17)$.

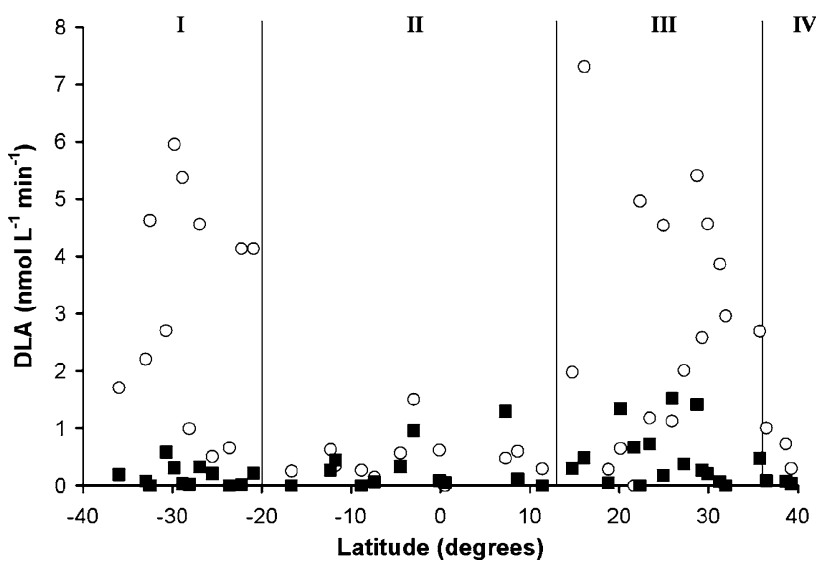

Fig. 1 Latitudinal distribution of data for DLA $\left(n m o l ~ L^{-1} \mathrm{~min}^{-1}\right)$ as plotted in Fig. 2a from Bell et al. (2007) but using the corrected values (note that the units have changed). Open circles denote surface samples and filled squares denote chlorophyll maximum samples. In this and subsequent figures, sections $I-I V$ (see text) are labelled along the top of the figure and indicated by solid vertical lines 


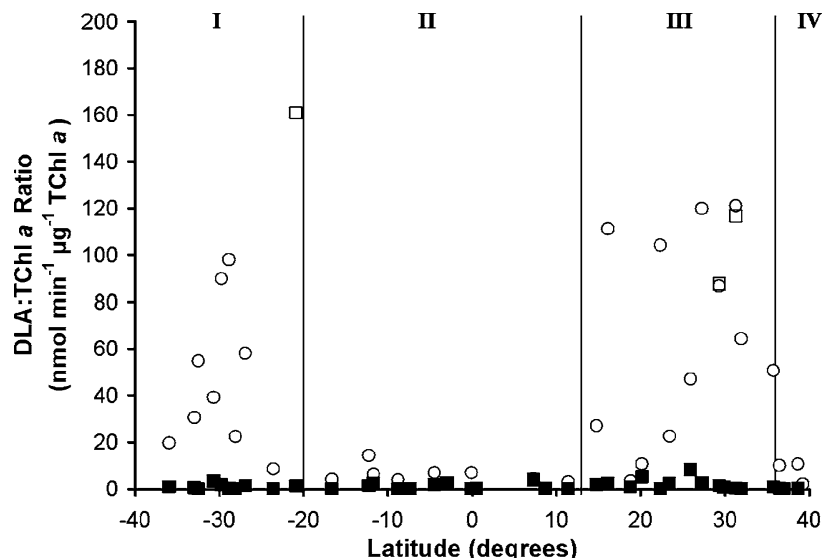

Fig. 2 Latitudinal distribution of data for DLA:TChl $a$ (nmol $\mathrm{min}^{-1} \mu \mathrm{g}^{-1} \mathrm{TChl} a$ ) as plotted in Fig. 2c from Bell et al. (2007) but using the corrected values (note that the units have changed). Open circles (HPLC chlorophyll) and squares (acetone-extracted chlorophyll) denote surface samples. Filled squares denote chlorophyll maximum samples

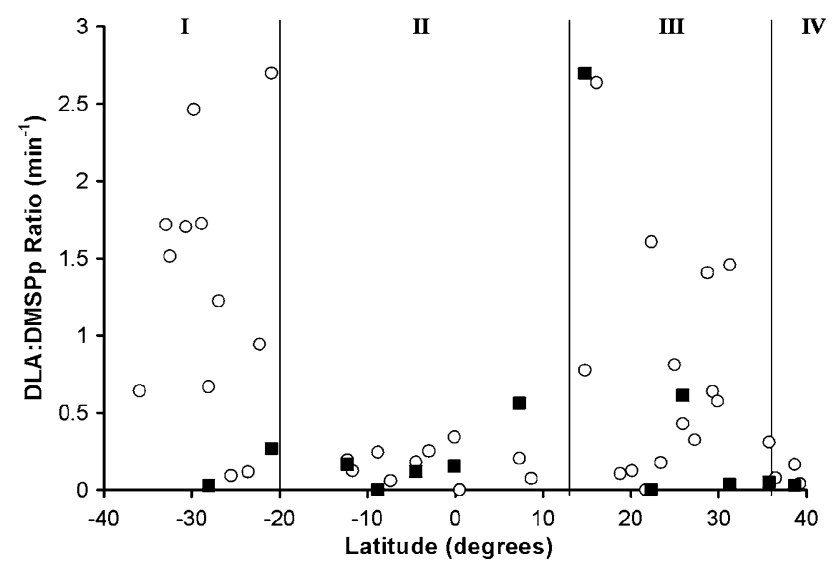

Fig. 3 Latitudinal distribution of data for DLA:DMSPp $\left(\mathrm{min}^{-1}\right)$ as plotted in Fig. 3d from Bell et al. (2007) but using the corrected values (note that the units have changed). Open circles denote surface samples and filled squares denote chlorophyll maximum samples

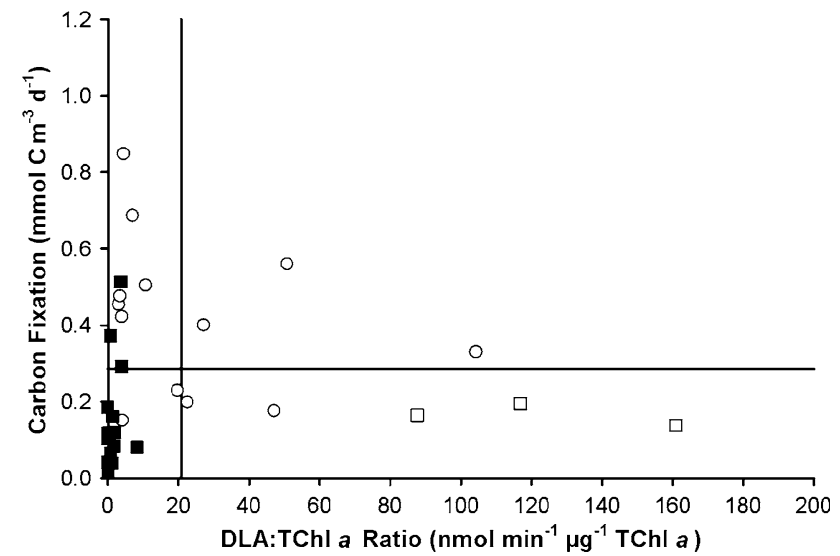

Fig. 4 Plot of phytoplankton carbon fixation $\left(m m o l ~ \mathrm{C} \mathrm{m}^{-3} \mathrm{~d}^{-1}\right)$ versus DLA:TChl $a\left(\mathrm{nmol} \mathrm{min}^{-1} \mu^{-1} \mathrm{TChl} a\right.$ ) as plotted in Fig. 4 from Bell et al. (2007) but using the corrected values (note that the units have changed). Open circles (HPLC chlorophyll) and squares (acetone-extracted chlorophyll) denote surface samples. Filled squares denote chlorophyll maximum samples. The mean concentrations for carbon fixation $\left(0.28 \mathrm{mmol} \mathrm{C} \mathrm{m}{ }^{-3} \mathrm{~d}^{-1}\right)$ and DLA:TChl $a$ $\left(20.8 \mathrm{nmol} \mathrm{min}{ }^{-1} \mu \mathrm{g}^{-1} \mathrm{TChl} a\right.$ ) are plotted as solid lines on the vertical and horizontal axes

Table 1 Surface DLA values from pre-dawn (PD) and late-morning (LM) CTD casts as shown in Table 1 from Bell et al. (2007) but using the corrected values (note that the units have changed). Each PD and LM sample pair was selected from the same day and was from the same section (sections described in original paper). The final column represents the difference between LM and PD. Sections I and III demonstrate elevated DLA in the LM cast relative to the same day's PD cast, with the exception of two days in section III (20 May 2004 and 23 May 2004)

\begin{tabular}{llllr}
\hline Section & $\begin{array}{l}\text { Date } \\
\text { (May }\end{array}$ & $\begin{array}{l}\text { Pre-dawn (PD) } \\
\left(\mathrm{nmol} \mathrm{L} \mathrm{min}^{-1}\right)\end{array}$ & $\begin{array}{l}\text { Late-morning (LM) } \\
\left(\mathrm{nmol} \mathrm{L} \mathrm{min}^{-1}\right)\end{array}$ & $\mathrm{LM} \mathrm{PD}$ \\
\hline I & 5th & 2.20 & 4.62 & 2.42 \\
I & 6th & 2.70 & 5.96 & 3.26 \\
I & 7th & 0.99 & 4.56 & 3.57 \\
II & 11 th & 0.63 & 0.35 & -0.28 \\
II & 12 th & 0.27 & 0.15 & -0.12 \\
II & 13 th & 0.57 & 1.50 & 0.93 \\
II & 14 th & 0.62 & 0.00 & -0.62 \\
II & 16 th & 0.48 & 0.60 & 0.12 \\
III & 18 th & 1.98 & 7.31 & 5.33 \\
III & 19th & 0.29 & 0.65 & 0.36 \\
III & 20th & 4.96 & 1.18 & -3.78 \\
III & 21st & 1.12 & 2.01 & 0.89 \\
III & 22nd & 2.59 & 4.57 & 1.98 \\
III & 23rd & 3.87 & 2.96 & -0.91 \\
IV & 26th & 0.73 & 0.30 & -0.43 \\
\hline
\end{tabular}




\section{References}

Bell TG, Malin G, Steinke M, Kim YN (2007) Spatial variability in DMSP-lyase activity along an Atlantic meridional transect. Aquat Sci 69:320-329
Harada H, Rouse MA, Sunda W, Kiene RP (2004) Latitudinal and vertical distributions of particle-associated dimethylsulfoniopropionate (DMSP) lyase activity in the western North Atlantic Ocean. Can J Fish Aquat Sci 61:700-711 